\title{
The Application of NIOSH Lifting Equation to Prevent Musculoskeletal Disorder Risks
}

\author{
Parvena Meepradit ${ }^{1}$, Nipoporn Sunee1, Ruephuwan Chantrasa ${ }^{2}$ \\ ${ }^{1}$ Department of Industrial Hygiene and Safety, Faculty of Public Health, Bangsaen, Thailand \\ ${ }^{2}$ Department of Industrial Engineering, Faculty of Engineering, Burapha University, Bangsaen, Thailand \\ Email: pravena15@yahoo.com
}

Received January 2015

\begin{abstract}
The objective of the study was to reduce musculoskeletal disorder risks by applying the NIOSH lifting equation variables include the horizontal location, the vertical location, the vertical travel distance, the asymmetric, the lifting frequency and the coupling classification. The 17 specific samples from 4W and ZECP division were selected by the weight of box $15.4-28.7$ pounds. The standardized Nordic questionnaire for the analysis of musculoskeletal symptoms with pain scale from 0 (no pain) to 10 (worst pain) was used to self-report feeling. The ergonomics redesigns trained for the workers included: 1) brought the load closer to the worker by training; 2) raised the height of objects placed to reduce the vertical distance between the origin and destination of the lift; and 3) moved the origin and destination of lift closer together to reduce the angel twist. The new procedures were trained to all participated workers. The result found that the lifting index was safer ( $\leq 1.0)$. For successful outcome, be supposed to monitoring is careful the data about a problem of the worker health, give the carefulness in case of specially exceed environment more than the LI advises and should do training continuously.
\end{abstract}

Keywords

NIOSH Lifting Equation, Musculoskeletal Disorder Risks

\section{Introduction}

In 2013 the Department of Labor Protection and Welfare, Thailand reported the amount of occupational disease was 131,826 cases that had 1335 workers (1.01\%) who lifted or moved the heavy object [1]. The result from many research also found the low back pain or injury cause from moving or lifting object majority. The direct and indirect loss from disease is the treatment expense, losing work hour, being caused the symptoms feels pain to go up discouraging mind in the work as the result of sickness.

The NIOSH (National Institute for Occupational Safety and Health) is an institute where dare to the office researches occupational health and safety of the United States of America. They do the development go up the equation for use to assess lifting of manually conveniently in the usability more and more, since 1981 by specify the risk factor in the work at might cause dangerous the muscle system and bone compose the material weight,

How to cite this paper: Meepradit, P., Sunee, N. and Chantrasa, R. (2015) The Application of NIOSH Lifting Equation to Prevent Musculoskeletal Disorder Risks. Journal of Biosciences and Medicines, 3, 39-44. 
the distance from the center of gravity of the material and a labor, frequency, period of time, work rhythm, the stability of the material and the convenience for lifting (the character of the material), and have the adaptation set up in 1991 and 1993 [2]. Thus in this researches, the researcher do interested in the importance in work condition adaptation to be safe for the worker who performs about manual lifting in an auto-part factory at might have the condition risks to build abnormality occurrence is lower back area, by taking the factors of the equation come to use for adaptation work condition, and assess compare with before and after by using the related factors of NIOSH lifting equation for decreasing the risk might have an effect on to the low back pain symptoms and give the worker has the safety permanently.

\section{Objectives}

1) To assess the work condition of manual lifting by the factors of NIOSH lifting equation.

2) To adjust the work condition of manual lifting as follow the factors of NIOSH lifting equation suggestion.

3) To compare the work condition of manual lifting by using Lifting Index (LI).

\section{Research Design}

The research design is semi-experimental research. The study period was during the January to March 2013. The population was 124 workers who lifted the box of auto-parts in the process. The 17 specific samples from $4 \mathrm{~W}$ and ZECP division were selected by the weight of box $15.4-28.7$ pounds and the frequency $0.5-2$ lift per minute. They had no chronic low back pain (past 12 month) during lifting and willing to be the participants.

The tools were used for two objectives. The first used for measuring the distance factors for example, weighing apparatus, the distance, the angle measuring equipment as the NIOSH lifting equation variables. The low back pain feeling during lift was applied from the standardized Nordic questionnaire for the analysis of musculoskeletal symptoms with pain scale from 0 (no pain) to 10 (worst pain) [3].

The study methods after asked for the establishment's permission the primary data was collected the processes, the lifting procedures and the work duration. Measuring the variable data about the manual lifting condition as follow the NIOSH lifting equation ${ }^{2}$ both the origin (o) and destination (d), thus, the weight of the object lifted, the distance from the wrist in horizontal $(\mathrm{H})$ measured in inches, the distance from the wrist in the vertical $(\mathrm{V})$ measured in inches, movement distance of a hand $(\mathrm{D}=\mathrm{Vd}-\mathrm{Vo})$ measured in inches, the angle of the shoulder from usual by measure in flat line (A), the frequency of lifting (F) per minute and holding work character (C). The Multipliers were calculated from all variables at [4]. As the follow;

1) The horizontal multiplier $(\mathrm{HM})=10 / \mathrm{H}$.

2) The vertical multiplier $(\mathrm{VM})=(1-(0.0075|\mathrm{~V}-30|))$.

3) The distance multiplier $(\mathrm{DM})=(0.82+(1.8 / \mathrm{D})$.

4) The asymmetric multiplier $(\mathrm{AM})=(1-(0.0032 \mathrm{~A}))$.

5) The frequency multiplier (FM) from Table 1.

6) The coupling multiplier (CM) from Table 2.

Then calculated the Recommended Weight Limit (RWL) by multiplies all multiplier in 4.with the load constant (LC) 51 pounds. Finally, the lifting index (LI) was analyzed by divide the RWL with the object weight. The evaluating the lifting index (LI) as below;

1) $\mathrm{LI} \leq 1.0$ the present object weight or lifting procedures may be not effect to worker health.

2) $\mathrm{LI} \geq 2.0$ but not exceed 3.0 show the present manual lifting task risk to cause of the low back pain (LBP) symptoms.

3) LI > 3.0 the worst case of handle lifting. It cause to low back injury.

The ergonomics redesign need for the workers and workplace improvement included: 1) brought the load closer to the worker by training; 2) raised the height of objects placed to reduce the vertical distance between the origin and destination of the lift; and 3) moved the origin and destination of lift closer together to reduce the angel twist. The new procedures were trained to all participated workers. The final evaluation was measured the NOISH lifting equation multipliers again that the lifting index value should less than 1.0.

\section{Results}

1) The 17 samples who worked in auto parts manufacturing as the box lifting with different sizes by weighted 15.7 - 28.7 pounds with the duration 1 - 4 hours a day, by way of lifting that always needs to be reached or 
Table 1. The frequency multiplier (FM).

\begin{tabular}{|c|c|c|c|c|c|c|}
\hline \multirow{3}{*}{$\begin{array}{l}\text { Frequency } \\
\text { lift/min } \\
(\mathrm{F})^{*}\end{array}$} & \multicolumn{6}{|c|}{ Work duration } \\
\hline & \multicolumn{2}{|c|}{$\leq 1$ Hour } & \multicolumn{2}{|c|}{$>1 \leq 2$ Hours } & \multicolumn{2}{|c|}{$>2$ but $\leq 8$ Hours } \\
\hline & $\mathrm{V}<30$ inches & $V \geq 30$ inches & $\mathrm{V}<30$ inches & $\mathrm{V} \geq 30$ inches & $\mathrm{V}<30$ inches & $V \geq 30$ inches \\
\hline$\leq 0.2$ & 1.00 & 1.00 & 0.95 & 0.95 & 0.85 & 0.85 \\
\hline 0.5 & 0.97 & 0.97 & 0.92 & 0.92 & 0.81 & 0.81 \\
\hline 1 & 0.94 & 0.94 & 0.88 & 0.88 & 0.75 & 0.75 \\
\hline 2 & 0.91 & 0.91 & 0.84 & 0.84 & 0.65 & 0.65 \\
\hline 3 & 0.88 & 0.88 & 0.79 & 0.79 & 0.55 & 0.55 \\
\hline 4 & 0.84 & 0.84 & 0.72 & 0.72 & 0.45 & 0.45 \\
\hline 5 & 0.80 & 0.80 & 0.60 & 0.60 & 0.35 & 0.35 \\
\hline 6 & 75 & 75 & 0.50 & 0.50 & 0.27 & 0.27 \\
\hline 7 & 0.70 & 0.70 & 0.42 & 0.42 & 0.22 & 0.22 \\
\hline 8 & 0.60 & 0.60 & 0.35 & 0.35 & 0.18 & 0.18 \\
\hline 9 & 0.52 & 0.52 & 0.30 & 0.30 & 0.00 & 0.15 \\
\hline 10 & 0.45 & 0.45 & 0.26 & 0.26 & 0.00 & 0.13 \\
\hline 11 & 0.41 & 0.41 & 0.00 & 0.23 & 0.00 & 0.00 \\
\hline 12 & 0.37 & 0.37 & 0.00 & 0.21 & 0.00 & 0.00 \\
\hline 13 & 0.00 & 0.34 & 0.00 & 0.00 & 0.00 & 0.00 \\
\hline 14 & 0.00 & 0.31 & 0.00 & 0.00 & 0.00 & 0.00 \\
\hline 15 & 0.00 & 0.28 & 0.00 & 0.00 & 0.00 & 0.00 \\
\hline$>15$ & 0.00 & 0.00 & 0.00 & 0.00 & 0.00 & 0.00 \\
\hline
\end{tabular}

*For lifting less frequency than once per 5 minutes, set F = 0.2 lifts/minute; Application manual for the revised NIOSH lifting equation, 1994 [2].

Table 2. The coupling multiplier.

\begin{tabular}{ccc}
\hline & \multicolumn{2}{c}{ Coupling multiplier } \\
\cline { 2 - 3 } Coupling type & $\mathrm{V}<30$ inches & $\mathrm{V} \geq 30$ inches \\
\hline Good & 1.00 & 1.00 \\
Fair & 0.95 & 1.00 \\
Poor & 0.90 & 0.90 \\
\hline
\end{tabular}

Application manual for the revised NIOSH lifting equation, 1994 [2].

twisted as the awkward postures. The subject feeling at the low back pain before redesign found that the level at 5, 7, 9 and 10 mostly (17.65\%). The subject feeling at the low back pain after redesign found that the level at 6 mostly (29.41\%) and the pain feeling at 9 and 10 disappeared as shown in Table 3.

2) The multipliers of those NIOSH parameters were used to calculate the RWL (Recommended weight limit) of the origin and destination of the lift. The results from all position of workplace before redesign found that the mean HM, VM, DM, AM and FM were less than 1, while the CM was equal to 1 in all areas. The RWL highest was 27.85 pounds at the origin of the $4 \mathrm{~W}$ calcination. The RWL lowest was 10.12 pounds at the destination of the ZECP input as shown in Table 4.

The results from all position of workplace after ergonomics redesign found that the mean HM, VM, DM, AM and FM were increased closer than 1. The RWL of all workplaces was increased as the highest 40.44 pound and the lowest 28.83 pound as detailed in Table 5.

3) The lifting index (LI) as the load 15.4, 17.6, 19.8, 22.1, 24.3, 26.5 and 28.7 pounds found more than 1.0 at the origin and destination of all workplace. However after redesign the LI found less than 1.0 at the origin and destination of all workplace.

\section{Discussion}

The recommended weigh limit (RWL) after redesign of existing manual lifting job depend on the guide of NIOSH equation including included the brought the load closer to the worker, raised the height of objects placed to reduce the vertical distance between the origin and destination of the lift and moved the origin and destination of lift closer together to reduce the angel twist were increasing. That mean the workers can lift heavier than 
Table 3. The low back pain feeling of the workers.

\begin{tabular}{|c|c|c|}
\hline \multirow{2}{*}{ The low back pain level } & \multicolumn{2}{|c|}{ Worker (n = 17) } \\
\hline & Before redesign & After redesign \\
\hline 0 & $0(0.00)$ & $0(0.00)$ \\
\hline 1 & $0(0.00)$ & $0(0.00)$ \\
\hline 2 & $1(5.88)$ & $3(17.65)$ \\
\hline 3 & $1(5.88)$ & $0(0.00)$ \\
\hline 4 & $1(5.88)$ & $3(17.65)$ \\
\hline 5 & $3(17.65)$ & $4(23.53)$ \\
\hline 6 & $2(11.76)$ & $5(29.41)$ \\
\hline 7 & $3(17.65)$ & $1(5.88)$ \\
\hline 8 & $0(0.00)$ & $1(5.88)$ \\
\hline 9 & $3(17.65)$ & $0(0.00)$ \\
\hline 10 & $3(17.65)$ & $0(0.00)$ \\
\hline
\end{tabular}

Table 4. The average of variable multipliers and RWL before redesign.

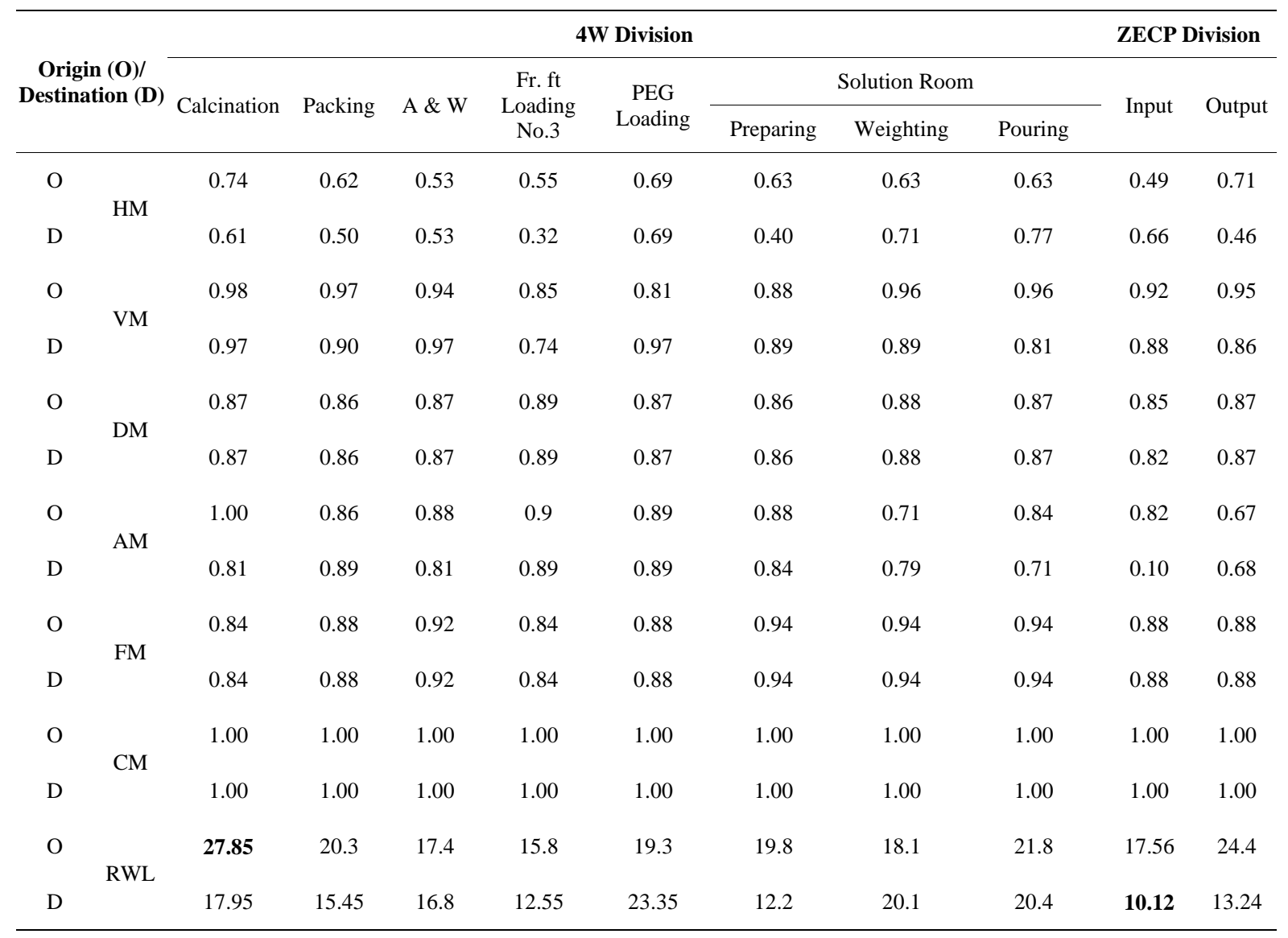


Table 5. The average of variable multipliers and RWL after redesign.

\begin{tabular}{|c|c|c|c|c|c|c|c|c|c|c|c|}
\hline \multirow{3}{*}{\multicolumn{2}{|c|}{$\begin{array}{l}\text { Origin (O)/ } \\
\text { Destination } \\
\text { (D) }\end{array}$}} & \multicolumn{8}{|c|}{ 4W Division } & \multicolumn{2}{|c|}{ ZECP Division } \\
\hline & & \multirow{2}{*}{ Calcination } & \multirow{2}{*}{ Packing } & \multirow{2}{*}{$A \& W$} & \multirow{2}{*}{$\begin{array}{c}\text { Fr. ft } \\
\text { Loading } \\
\text { No.3 }\end{array}$} & \multirow{2}{*}{$\begin{array}{c}\text { PEG } \\
\text { Loading }\end{array}$} & \multicolumn{3}{|c|}{ Solution Room } & \multirow{2}{*}{ Input } & \multirow{2}{*}{ Outpu } \\
\hline & & & & & & & Preparing & Weighting & Pouring & & \\
\hline $\mathrm{O}$ & \multirow{2}{*}{ HM } & 0.91 & 0.92 & 1 & 1 & 0.96 & 0.93 & 0.93 & 0.93 & 0.94 & 0.94 \\
\hline $\mathrm{D}$ & & 1 & 0.75 & 1 & 1 & 0.96 & 0.89 & 0.89 & 0.89 & 0.87 & 0.96 \\
\hline $\mathrm{O}$ & \multirow[b]{2}{*}{ VM } & 1 & 0.98 & 0.98 & 0.98 & 0.93 & 0.89 & 0.89 & 0.89 & 0.96 & 0.97 \\
\hline $\mathrm{D}$ & & 0.96 & 0.96 & 1 & 1 & 0.95 & 0.96 & 0.96 & 0.96 & 0.97 & 0.94 \\
\hline $\mathrm{O}$ & \multirow{2}{*}{ DM } & 1 & 1 & 1 & 1 & 1 & 1 & 1 & 1 & 1 & 1 \\
\hline $\mathrm{D}$ & & 1 & 1 & 1 & 1 & 0.90 & 1 & 1 & 1 & 1 & 1 \\
\hline $\mathrm{O}$ & \multirow{2}{*}{$\mathrm{AM}$} & 0.90 & 0.98 & 0.90 & 0.90 & 0.90 & 0.95 & 0.95 & 0.95 & 0.98 & 0.98 \\
\hline $\mathrm{D}$ & & 0.95 & 0.88 & 0.88 & 0.88 & 0.95 & 0.81 & 0.81 & 0.81 & 0.94 & 0.94 \\
\hline $\mathrm{O}$ & \multirow{2}{*}{ FM } & 0.84 & 0.90 & 0.84 & 0.84 & 0.92 & 0.81 & 0.81 & 0.81 & 0.88 & 0.88 \\
\hline $\mathrm{D}$ & & 0.84 & 0.90 & 0.84 & 0.84 & 0.92 & 0.88 & 0.88 & 0.88 & 0.88 & 0.88 \\
\hline $\mathrm{O}$ & \multirow{2}{*}{$\mathrm{CM}$} & 1 & 1 & 1 & 1 & 1 & 1 & 1 & 1 & 1 & 1 \\
\hline $\mathrm{D}$ & & 1 & 1 & 1 & 1 & 1 & 1 & 1 & 1 & 1 & 1 \\
\hline $\mathrm{O}$ & \multirow{2}{*}{ RWL } & 35.09 & 40.09 & 37.78 & 37.78 & 37.50 & 35.29 & 35.29 & 35.29 & 39.48 & 39.81 \\
\hline $\mathrm{D}$ & & 39.07 & 28.83 & 37.70 & 37.70 & 40.44 & 31.06 & 31.06 & 31.06 & 35.09 & 38.00 \\
\hline
\end{tabular}

before improvement. In the other hand, the workers would be decreased the musculoskeletal disorder risk during lift the former load object at 15.4, 17.6, 19.8, 22.1, 24.3, 26.5 and 28.7 pounds. In addition the lifting index after ergonomic redesign found that less than 1.0 all weight.

All above we can conclude that the NIOSH lifting equation is a tool to evaluate a variety of two-handed manual lifting tasks and can be guideline to improve the working condition as follow the multiplier parameter. It presents illustrate distinct all over the worker, the person who dare to that relate and establishment executive. In opinion, the researcher would like to suggest for the other establishment as a result, can lead the trend aforementioned goes to develop for adjust the manual lifting tasks safety. However the specific measuring in the adaptation corrects anything should come from the worker opinion and consider the data about a problem of the health. Follow the research result of Wietske Kuijer and et al. (2006) [4] found that the RWL of worker who lift from the ground upwards at waist have the difference in the patient who has the symptoms aches chronic low back pain each. In addition, the environment of work condition value exceed the suggestion value of NISOH lifting equation should be considered specially, because of, the study of Prachuab Klomjit and Kitti Intaranont (2005) [5] found that some characteristic of work condition was outside to apply NIOSH lifting equation like lifting and walk for a short period and the environment that exceed temperature from the value advises might affect value specification RWL. For the way to improve working condition, should be easy and economize expenses for bring the cooperation of establishment executive and should fix training continuously, follow the education of, Jason J. Saleem, Brian M. Kleiner, and Maury A. Nussbaum (2003) [6] was suggested that should do training properly and combine with the other ergonomic tools.

\section{References}

[1] Division of Technical Services and Planning (2012) Labor Statistic Reporting 2012. Department of Labor Protection and Welfare. Labor Ministry.

[2] Waters, T.R., Putz-Anderson, V., Garg, A. and Fine, L.J. (1994) Applications Manual for the Revised NIOSH Lifting Equation. DHHS (NIOSH) Publication No. 94-110. U.S. Department of Health and Human Services, Chincinnati.

[3] Kuorinka, I., Jonsson, B., Kilbom, A., Vinterberg, H., Bierring-Sorensen, F. and Andersson, G., et al. (1987) Standar- 
dized Nordic Questionnaires for the Analysis of Musculoskeletal Symptoms. Applied Ergonomics, 18, 233-237. http://dx.doi.org/10.1016/0003-6870(87)90010-X

[4] Kuijer, W., et al. (2006) Comparing FCE Lifting Task and NIOSH Lifting Guideline. Journal of Occupational Rehabilitation, 16, 579-589. http://dx.doi.org/10.1007/s10926-005-9010-3

[5] Klomjit, P. and Intaranont, K. (2005) An Evaluation of Manual Lifting Tasks in the Factories by NIOSH Lifting Equation. KMUTT Research and Development Journal, 28, 331-334.

[6] Saleem, J.J., Kleiner, B.M. and Nussbaum, M.A. (2003) Empirical Evaluation of Training and a Work Analysis Tool for Participatory Ergonomics. International Journal of Industrial Ergonomics, 31, 387-396. http://dx.doi.org/10.1016/S0169-8141(03)00024-6 